\title{
SOME PHARYNGEAL JAW MUSCLES OF CALOTOMUS JAPONICUS (SCARIDAE, PISCES)
}

AUTHOR(S):

Yamaoka, Kosaku

\section{CITATION:}

Yamaoka, Kosaku. SOME PHARYNGEAL JAW MUSCLES OF CALOTOMUS JAPONICUS (SCARIDAE, PISCES). PUBLICATIONS OF THE SETO MARINE BIOLOGICAL LABORATORY 1980, 25(5-6): 315-322

\section{ISSUE DATE:}

1980-11-15

URL:

http://hdl.handle.net/2433/176008

RIGHT: 


\title{
SOME PHARYNGEAL JAW MUSGLES OF CALOTOMUS JAPONICUS (SGARIDAE, PISGES)
}

\author{
KosAKU YAMAOKA \\ Department of Fisheries, Kyoto University
}

With Text-figures $1-7$

\begin{abstract}
The pharyngeal jaw muscles of Calotomus japonicus were examined. The structure of the infrapharyngeal crusher is similar to that of cichlids and labrids. That is, the fourth levator externus inserts on the lower pharyngeal bone, and the levator posterior is composed of two heads, one inserting on the fourth cpibranchial and the other on the lower pharyngeal bone. The origin of the fourth levator externus is very specialized, being from a deep concavity on the neurocranium. It is conceivable that this specialization is correlated with the change of functional pattern of the pharyngeal jaw apparatus, and increases the relative importance of the fourth levator externus acting on the lower pharyngeal bone. The influence of this specialization on the shape of the brain, especially of the cerebellum, is discussed.
\end{abstract}

\section{Introduction}

Scarid fishes, together with labrid fishes, are classified together in the suborder Labroidei. They have a united lower pharyngeal bones, as do the many species of Cichlidae, Pomacentridae and Embiotocidae and it is one of the most conspicuous specializations of the pharyngeal jaw apparatus (PJA). An apparatus is defined as a collection of elements of which certain morphological features form a functional component (Dullemeijer and Barel, 1977). Making a comparison between the degree of the PJA's development and feeding habits of cichlids and labrids, it was found that there were distinct functional relations (Cichlid: Liem, 1973; Liem and Osse, 1975; Liem and Stewart, 1976; Witte and Barel, 1976; Labrid: Yamaoka, 1978). In addition, various morphological differentiations of the PJA, especially in the muscular elements, were found. Nelson (1967) stated that the gill arches of labroid fishes, with their powerful pharyngeal dentition, are among the most specialized of any of those of recent teleosts. It can also be hypothesized that the muscles accompanying the gill arch of labroid fishes are highly specialized. The purpose of this paper is to report a specialized morphological differentiation of some muscular elements of the PJA in a species of Scaridae (Calotomus japonicus).

1) Contributions from the Seto Marine Biological Laboratory, No. 661.

Publ. Seto Mar. Biol. Lab., XXV (5/6), 315-322, $1980 . \quad$ (Article 19) 


\section{Materials and Methods}

Six specimens of Calotomus japonicus were examined (SL. 7.5, 9.2, 10.8, 10.9, 13.1, $21.5 \mathrm{~cm}$, all collected at Shirahama, Wakayama Prefecture). Observation methods are the same as those of Yamaoka (1978), myological nomenclature follows that of Winterbottom (1974).

\section{Descriptions}

Levators externi series

According to Winterbottom (1974), the levators externi muscles usually connect the neurocranium to the epibranchials in teleosts. In C. japonicus there are three muscle bundles falling in this category. Each of these is slender and they insert on the first, second and third epibranchials (Fig. 1). They originate from the prootic just beneath the anterior hyomandibular articulation socket. The muscles at the origin site are weakly tendinous. A very stout muscle posterior to the third levator externus seems to be the fourth levator externus (Fig. 1). This muscle possesses a myoseptum, and originates from the wide region of the skull. Its posterior half arises from the triangular-like large and deep concavity on the neurocranium (Fig. 2). This concavity is medial to the posterior hyomandibular articulation socket. It reaches just ventral to the roof of the neurocranium dor-

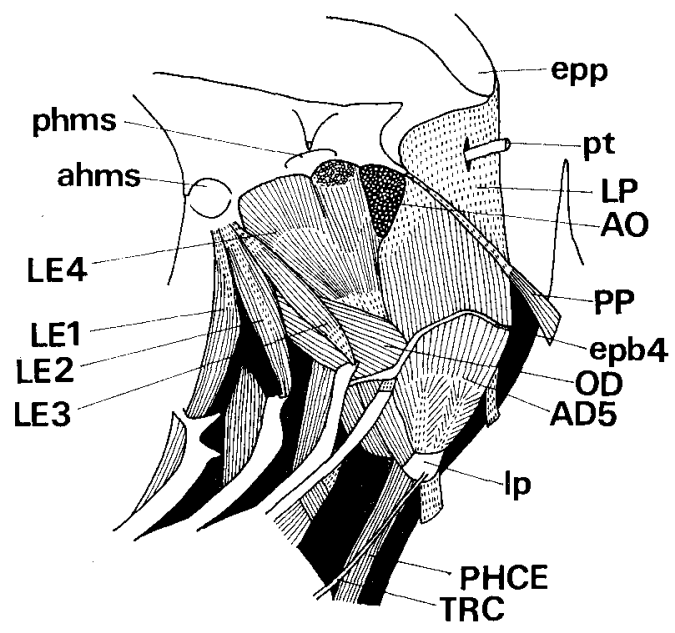

Fig. 1. Lateral view of branchial and pharyngeal region of Calotomus japonicus. Opercular and suspensory apparatus, gill filaments and mucous membrane removed. AD5, fifth adductor; AO, adductor operculi; LE1-4, first, second, third and fourth levator externus; LP, levator posterior; PHCE, pharyngoclavicularis externus; $\mathrm{PP}$, protractor pectoralis; $\mathrm{OD}$, obliquus dorsalis; TRC, tendon of rectus communis; ahms, anterior hyomandibular articulation socket; epp, epiotic process; lp, lower pharyngeal bone; hpms, posterior hyomandibular articulation socket; pt, ventral arm of posttemporal; epb 4, fourth epibranchial. 


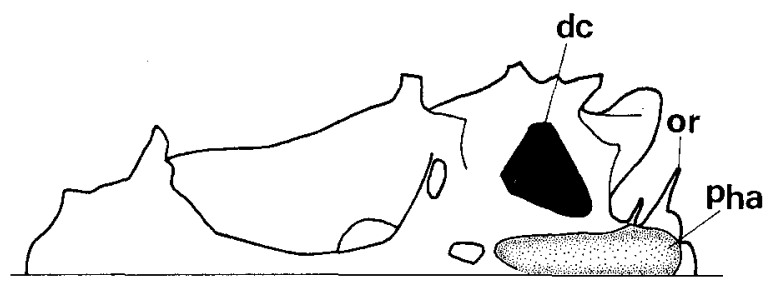

Fig. 2. Ventral view of neurocranium of C. japonicus. dc, deep concavity; or, occipital ridge; pha, pharnygeal apophysis.

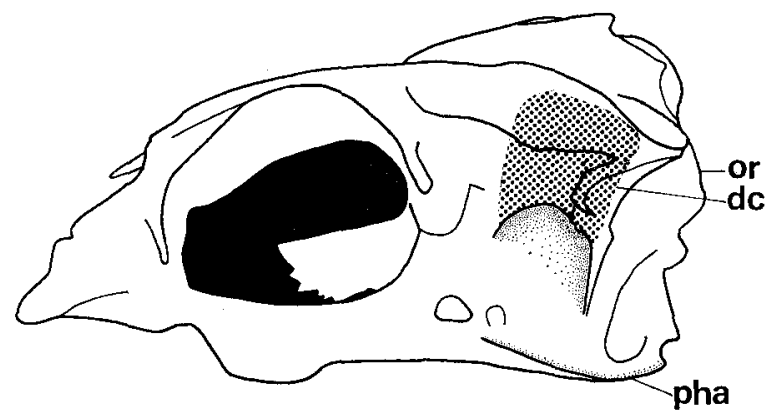

Fig. 3. Lateral view of neurocranium of C. japonicus. Symbols are same as in Fig. 2.

sally, and does not change in volume at the inner part (Fig. 3). The anteromost muscle fibers reach the ventromedial region of the anterior hyomandibular articulation socket. All muscle fibers bypass the fourth epibranchial medially and insert by a stout tendon on the lateral tip of the horn (muscular process) of the lower pharyngeal bone, just anterior to the insertion site of the levator posterior (Fig. 4). The tendon is almost fused with that of the levator posterior. Superficially, the origin is musculous, but among the muscle fibers some tendinous tissue develops. This muscle can be clearly distinguished from the levator posterior both laterally and medially and muscle fibers of the two do not mingle with each other. The adductor operculi passes between the two muscles. The ventral half of the fourth levator externus is covered laterally by the levator posterior, the obliquus dorsalis and the fifth adductor.

\section{Levators interni series}

There are two muscle bundles belonging to the levators interni series: second and third levators interni. The former lies medial to the first levator externus and the latter medial to the second levator externus. The third levator internus covers the second levator internus laterally at the origin site (Fig. 4). They originate from just medial to the sites of origin of the first, second and third levators externi. The origin is almost entirely musculous. The third levator internus inserts on the anterolateral region of the upper pharyngeal bone, whose dorsal face forms an elongate basipharyngeal joint with the pharyngeal apophysis (Figs. 2 and 3). Posterior 


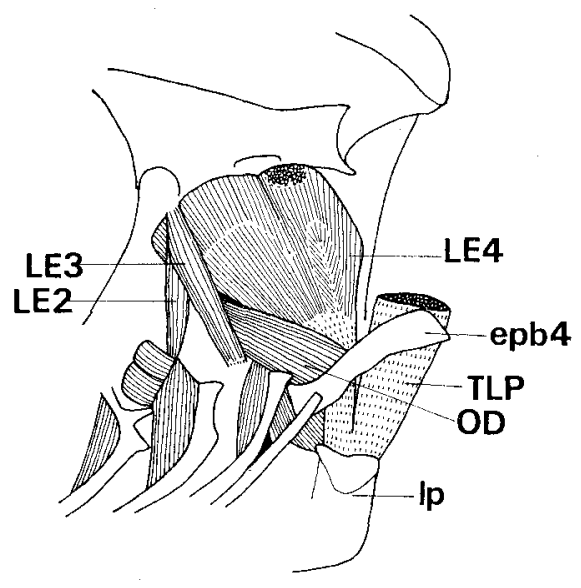

Fig. 4. Lateral view of branchial and pharyngeal region of C. japonicus. In addition to Fig. 1, muscle fibers of levator posterior, fifth adductor, first, second and third levator externus, adductor operculi and protractor pectoralis removed. LI2-3, second and third levator internus; TLP, tendon of levator posterior. Other symbols are same as in Fig. 1.

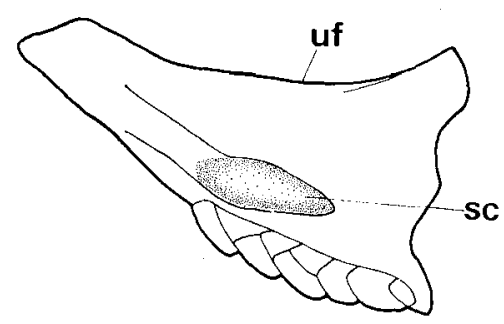

Fig. 5. Lateral view of upper pharyngeal bone of $C$. japonicus. sc, synovial condyle with fourth epibranchial; uf, upper face which form basipharyngeal joint with pharyngeal apophysis.

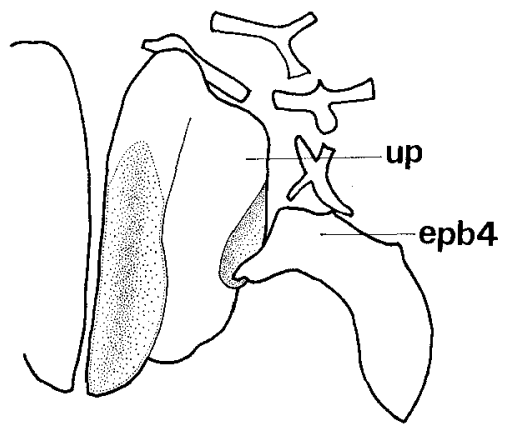

Fig. 6. Dorsal view of branchial and pharyngeal bones of C. japonicus. up, upper pharyngeal bone. Other symbol is same as in Fig. 1. 
to this insertion site, there is a synovial joint between the upper pharyngeal bone and the fourth epibranchial (Figs. 5 and 6). This muscle is the best developed muscle of the levators externi and interni series except for the fourth levator externus. The second levator internus does not insert on the upper pharyngeal bone but, passing ventrally anterior to the upper pharyngeal bone, on the second infrapharyngobranchial.

Levator posterior

This stout muscle is situated posterior to the fourth levator externus (Fig. 1). It originates mainly from the occipital and epiotic regions of the neurocranium. The occipital ridge (Figs. 2 and 3) is also included in site of origin. The dorsomediomost muscle fibers reach the base of the supraoccipital crest. Thus the degree of development of this muscle in this species falls under the category of Type Ba of labrids (Yamaoka, 1978). The muscle fibers originating in the region of the epiotic process are covered by a thick connective tissue layer. Ventral to the epiotic process, the ventral arm of the posttemporal passes at right angles through this muscle bundle (Fig. 1). The lateral fibers insert musculously on the hypertrophied fourth epibranchial, but the medial fibers bypass the fourth epibranchial and insert on the lateral tip of the horn (muscular process) of the lower pharyngeal bone by a stout, plate-like tendon (Fig. 4). Intermingled with the muscle fibers are connective tissue elements which are not consolidated into the tendon found in Type PA in labrids (Yamaoka, 1978). Superficially this muscle appears a parallel-fibered, but as a whole it is pinnate.

\section{Pharyngoclavicularis series}

The pharyngoclavicularis externus is a plate-like muscle originating musculously from the cleithrum and inserting on the anteroventral face of the tooth-bearing area of the lower pharyngeal bone (Fig. 1). At the site of insertion, a thin connective tissue membrane covers the muscle bundle. In $C$. japonicus this muscle is better developed than in labrids (pers. obs.). The pharyngoclavicularis internus is such a thin and weak muscle that it may easily be overlooked in the dissection. It lies medial to the pharyngoclavicularis externus and originates with aponeurosis from the cleithrum. The muscle fibers pass anterodorsally to insert on the lower ridge of the keel of the lower pharyngeal bone. The pharyngoclavicularis externus and p. internus cross almost rectangularly with each other. In this species, the pharyngoclavicularis internus is less well developed than in labrids (pers. obs.).

Retractor dorsalis

Origin is musculous from the first through fifth vertebrae. It inserts on the posterior face of the upper pharyngeal bone partly tendinously. The posteromost muscle fibers barely reach the medial face of the neural arch of the fifth vertebra. The neurocranium is not included in the site of origin. Except at the sites of origin and insertion, the muscle fibers fuse with those of the other half on the medial 
sagittal plane, where it is not easy to distinguish the left and right muscle bundles.

Rectus communis

This is a slender muscle connecting the dorsal edge of the urohyal to the lateroventral face of the horn (muscular process) of the lower pharyngeal bone. Muscle fibers grade into a long, slender tendon where they cross the pharyngoclavicularis externus (Fig. 1). The attachment to the lower pharyngeal bone is tendinous, that to the urohyal musculous.

Fifth adductor

This muscle connects the ventral face of the fourth epibranchial to the process of the lower pharyngeal bone (Fig. 1). As the fourth epibranchial is hypertrophied, this muscle develops well. Origin is mainly musculous, insertion partly tendinous.

Obliquus dorsalis

This muscle is much better developed than in labrids (pers. obs.). It connects the hypertrophied fourth epibranchial to the convexity of the anterior region of the upper pharyngeal bone (Figs. 1 and 4). It lies medial to the levators interni series.

\section{Discussion}

The sites of origin and insertion of muscles relating directly to the upper and lower pharyngeal bones in C. japonicus are similar to those of the infrapharyngeal crusher in cichlids (Liem, 1973; Liem and Osse, 1975) and labrids (Yamaoka, 1978). So it can be reasoned that the grinding power of the PJA is strong. There are, however, a few structural differences in this species. The most striking one is that of the origin of the fourth levator externus in a deep concavity of the neurocranium. By virtue of this change, it becomes an elongate muscle bundle which probably exhibits greater powers of contraction. In labrids the levator posterior is relatively more important (Yamaoka, 1978), but in this species, I suspect that the fourth levator externus is relatively more important. This change may be related to the more oblique angle of attach of the dental plates of both upper and lower pharyngeal bones (Fig. 5) than is found in labrids. The qualitative alteration in pharyngeal bone movements, may be related with the fact that this species, not a carnivore like labrids (Hashimoto, 1977), feeds on sea-weeds (Suyehiro, 1942) or sea-weeds and benthic animals (Masuda et al., 1975). For, if it is required only to strengthen the crushing power, it is not necessary to make such a remarkable change on bony elements as above-mentioned deep concavity. This increase in crushing power can be more easily achieved in the manner exhibited in Type PA in labrids (Yamoaka, 1978).

Other specialized morphological features are as follows: Of the two levators interni muscles, only the third levator internus inserts on the upper pharyngeal bone. The pharyngoclavicularis externus and the obliquus dorsalis are well developed and the pharyngoclavicularis internus only weakly developed as compared to 
labrids.

In compact system such as a fish head, the change of shape, size and position of an element will often affect the morphological features of surrounding elements (Dullemeijer and Barel, 1977). So it can be thought that a deep concavity from which the posterior half of the fourth levator externus originates may affect the shape of the cerebellum. In C. japonicus the cerebellum is rectangular-like in shape and seems to be compressed laterally (Fig. 7a) and weakly developed. A similar shape is found also in labrids (Fig. 7b), but generally there is not a deep cancavity

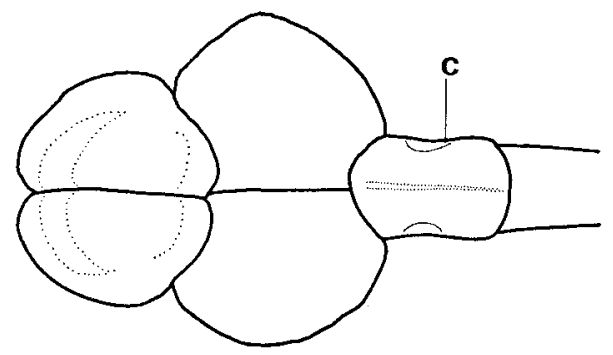

a

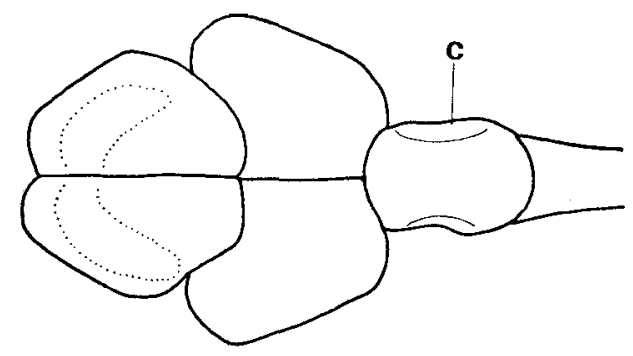

b

Fig. 7. Dorsal view of brain. a; C. japonicus. b; Thalassoma cupido (a labrid). c, cerebellum.

but a fatty substance between the epiotic process and the cerebellum. If it is accepted that the labrid is less specialized than the scarid (Matsubara, 1963; Nelson, 1967), I guess that the cerebellum of the labrids has already approached that of C. japonicus in shape. Thus the situation of a few elements of different organs at the posterior region of the neurocranium in the labrids shows a preadaptation for the origin of the fourth levator externus of $C . j$ japonicus from a deep concavity without causing a serious change in the shape of the brain. Since interaction of the functional components is of much significant in evolutionary biology (Dullemeijer and Barel, 1977), it would be interesting to compare the degree of development of the PJA with the form of the brain in detail in labrid and scarid fishes. 


\section{Acknowledgements}

I am extremely grateful to Professor Tamotsu Iwai of Kyoto University for his encouragements, generousity and critical readings of the manuscript. I would also like to express my special thanks to following people for their helpful advice and encouragements; Mr. Tetsuo Yoshino, University of Ryukyus, Messrs. Mutsumi Nishida, Ryuzo Fukao and Testuo Kuwamura, Kyoto University. I am very thankful to Dr. Richard Winterbottom for his critical reading of the manuscript.

\section{REFERENCES}

Dullemeijer, P. and C.D.N. Barel. 1977. Functional morphology and evolution. In: Major patterns in vertebrate evolution. NATO advanced study institute. Plenum Press, New York and London, Ser. A, 14, 83-117.

Hashimoto, J. 1977. A study of feeding habits of the reef fishes in the Nansei Islands. Kŕanos OÍKO (Bulletin of the Marine Ecological Researching Society of Kagoshima University), 18, 2-122. (In Japanese).

Liem, K.F. 1973. Evolutionary strategies and morphological innovations: Cichlid pharyngeal jaws. Syst. Zool., 22, 425-441.

Liem, K.F. and J.W.M. Osse. 1975. Biological versatility, evolution and food resource exploitation in African cichlid fishes. Amer. Zool., 15, 427-454.

Liem, K.F. and D.J. Stewart. 1976. Evolution of the scale-eating cichlid fishes of Lake Tanganyika: A generic revision with a description of a new species. Bull. Mus. Comp. Zool., 147, 319-350.

Masuda, H., C. Araga and T. Yoshino. 1975. Coastal fishes of southern Japan. Tokai Univ. Press, Tokyo, 1-379.

Matsubara, K. 1963. Systematic Zoology. vol. 9, Pisces. Nakayama Shoten, Tokyo, 1-531. (In Japanese).

Nelson, G.J. 1967. Gill arches of some teleostean fishes of the families Girellidae, Pomacentridae, Embiotocidae, Labridae and Scaridae. J. nat. Hist., 1, 289-293.

Suyehiro, Y. 1942. A study on the digestive system and feeding habits of fish. Japan. J. Zool., 10(1), $1-301$.

Winterbottom, R. 1974. A descriptive synonymy of the striated muscles of the Teleostei. Proc. Acad. Nat. Sci. Philadelphia, 125, 225-312.

Witte, F. and C.D.N. Barel. 1976. The comparative functional morphology of the pharyngeal jaw apparatus of piscivorous and infrapharyngeal mollusc-crushing Haplochromis species. Rev. Trav. Inst. Peches marit., 40(3 et 4), 793-796.

Yamaoka, K. 1978. Pharyngeal jaw structure in labrid fish. Publ. Seto Mar. Biol. Lab., 24, 409-426. 